\title{
Prevalence of antibody to hantaviruses in humans and rodents in the Caribbean region of Colombia determined using Araraquara and Maciel virus antigens
}

\author{
Camilo Guzmán 1 , Salim Mattar ${ }^{1 /+}$, Silvana Levis ${ }^{2}$, Noemí Pini², \\ Tadeu Figueiredo ${ }^{3}$, James Mills ${ }^{4}$, Jorge Salazar-Bravo ${ }^{5}$
}

\begin{abstract}
${ }^{1}$ Instituto de Investigaciones Biológicas del Trópico, Universidad de Córdoba, Montería, Colombia
${ }^{2}$ Instituto Nacional de Enfermedades Virales Humanas Dr Julio I Maiztegui Pergamino, Argentina ${ }^{3}$ Centro de Pesquisa em Virologia, Faculdade de Medicina de Ribeirão Preto, Universidade de São Paulo, São Paulo, SP, Brasil ${ }^{4}$ Centers for Disease Control and Prevention, Medical Ecology, Atlanta, GA, USA ${ }^{5}$ Department of Biological Sciences, Texas Tech University, Lubbock, TX, USA
\end{abstract}

We tested sera from 286 agricultural workers and 322 rodents in the department of Córdoba, northeastern Colombia, for antibodies against two hantaviruses. The sera were analysed by indirect ELISA using the lysate of Vero E6 cells infected with Maciel virus (MACV) or the N protein of Araraquara virus (ARAV) as antigens for the detection of antibodies against hantaviruses. Twenty-four human sera were IgG positive using one or both antigens. We detected anti-MACV IgG antibodies in $10 \mathrm{sera}(3.5 \%)$ and anti-ARAV antibodies in 21 sera $(7.34 \%)$. Of the 10 samples that were positive for MACV, seven (70\%) were cross-reactive with ARAV; seven of the 21 ARAV-positive samples were cross-reactive with MACV. Using an ARAV IgM ELISA, two of the 24 human sera (8.4\%) were positive. We captured 322 rodents, including 210 Cricetidae (181 Zygodontomys brevicauda, 28 Oligoryzomys fulvescens and 1 Oecomys trinitatis), six Heteromys anomalus (Heteromyidae), one Proechimys sp. (Echimyidae) and 105 Muridae (34 Rattus rattus and 71 Mus musculus). All rodent sera were negative for both antigens. The $8.4 \%$ detection rate of hantavirus antibodies in humans is much higher than previously found in serosurveys in North America, suggesting that rural agricultural workers in northeastern Colombia are frequently exposed to hantaviruses. Our results also indicate that tests conducted with South American hantavirus antigens could have predictive value and could represent a useful alternative for the diagnosis of hantavirus infection in Colombia.

Key words: hantavirus - Colombia - epidemiological surveillance - Rodentia - public health - immunoassay

Hantaviruses (family Bunyaviridae, genus Hantavirus) are rodent-borne zoonotic viruses that produce two major clinical syndromes in humans: haemorrhagic fever with renal syndrome in Asia and Europe and hantavirus pulmonary syndrome (HPS) in the Americas. Since HPS was initially characterised in the United States of America (USA) in 1993 and since the associated hantavirus Sin Nombre virus (SNV) was identified, increasing numbers of human cases and SNV-related viruses have been identified in different countries of North and South America (Puerta et al. 2006).

All hantaviruses that cause HPS are hosted by rodents of the family Muridae, subfamily Sigmodontinae (New World rats and mice). Since the original characterisation of SNV in 1993, approximately 25 hantavirus genotypes from the Americas have been described; each is associated with a different rodent species or subspecies (Levis et al. 1998, Padula et al. 2000). Hantaviruses have been documented in South America in Argentina (Levis et al. 1998), Chile, Paraguay, Uruguay, Bolivia

Financial support: UCO, Colombia

+ Corresponding author: mattarsalim@hotmail.com

Received 16 May 2012

Accepted 14 September 2012
(Padula et al. 2000), Brazil (Moreli et al. 2004) and Venezuela (Fulhorst et al. 1997, Rivas et al. 2003) and in Central America in Panama (Vincent et al. 2000).

Although reported in two bordering countries, human cases of hantavirus infection have not been documented in Colombia.

Maciel virus (MACV) and Araraquara virus (ARAV), which were isolated and characterised in Argentina and Brazil, respectively, are two autochthonous South American hantaviruses that have been used to produce ELISAs (Levis et al. 1998, Figueiredo et al. 2009). Although these assays have been used independently, no study has compared their relative levels of sensitivity using the same samples, especially in areas outside of Argentina and Brazil. These assays are likely to vary in sensitivity (Figueiredo et al. 2009), however, because MACV and ARAV are closely related phylogenetically, share at least $85 \%$ identity in the S segment, which encodes the N protein (Raboni et al. 2005), and share the same reservoir host (Calderón et al. 1999, Suzuki et al. 2004, D’Elía et al. 2008), we expected that their sensitivities would be similar. In addition, previous studies on hantavirus antibody prevalence in the Caribbean region of Colombia have used SNV antigen and it may be expected that tests using South American antigens would have greater sensitivity and specificity.

Our objective was to determine the prevalence of hantavirus antibodies in humans and rodents in the department of Córdoba, northeastern Colombia, using an- 
tigens from two South American hantaviruses, ARAV and MACV. We also compared the results of the tests using these two antigens and we compared the results of both tests to the results using the SNV antigen for a subsample of antibody-positive human sera.

\section{SUBJECTS, MATERIALS AND METHODS}

The study was divided into two phases. The first phase was prospective and was conducted between November 2008-January 2009 in three municipalities of Córdoba. The second phase was retrospective and included sera from healthy farmers collected in 2002, 2004 and 2005 in the same area of Córdoba included in the prospective phase.

Study area - Córdoba is located in the northeastern Caribbean area of Colombia. Our study included the municipalities of Planeta Rica ( $8^{\circ} 4^{\prime} 33.26^{\prime \prime} \mathrm{N} 75^{\circ} 35^{\prime} 11.47^{\prime}$ 'W), Lorica $\left(9^{\circ} 14^{\prime} 11.87^{\prime \prime} \mathrm{N} 75^{\circ} 48^{\prime} 54.47^{\prime \prime} \mathrm{W}\right)$ and Sahagún ( $8^{\circ} 56^{\prime} 5.33^{\prime \prime} \mathrm{N} 75^{\circ} 20^{\prime} 99^{\prime \prime} \mathrm{W}$ ) (Figure). These locations were selected because antibodies against SNV were found in humans and rodents in previous studies (Mattar \& Parra 2004, Alemán et al. 2006). The general topography is characterised by the outlying spurs of the Caribbean savannahs. The area is partially covered by dense tropical forest vegetation. The forest is now fragmented and has been modified by human agricultural activities. The primary cultivated crops are corn, rice, vegetables, citrus and other tropical fruits, including bananas, mango, guava, avocados and papayas. Agriculture, primarily involving manual labour, is the main source of employment. The housing for the agricultural labourers is typically of poor construction and in many cases it consists of shacks of salvaged wood, palms and sheet metal. The domestic and peridomestic habitats are characterised by poor sanitation and easy access for rodents. In previous studies, infection was found even in the urban areas.

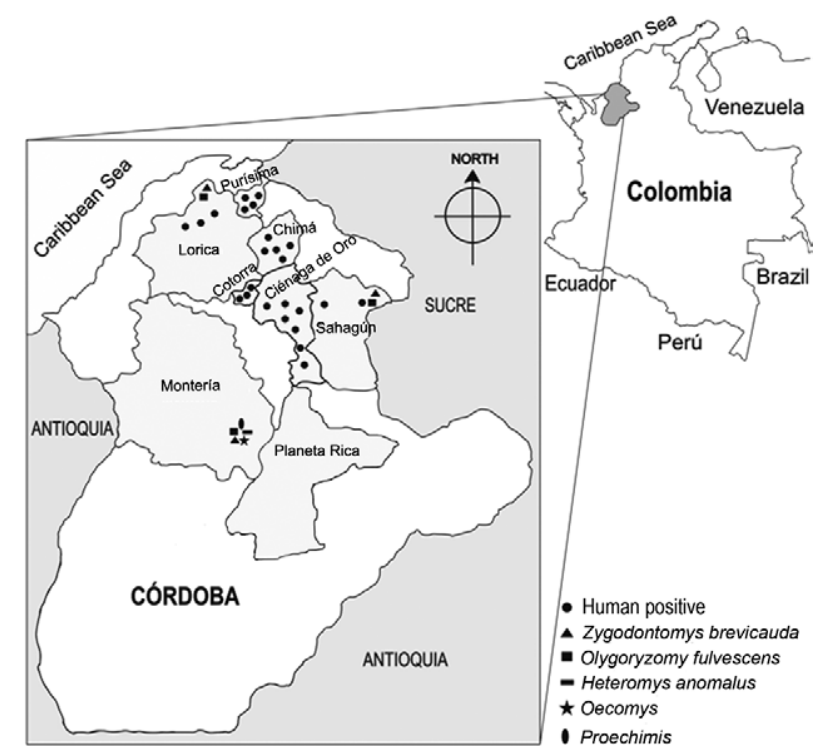

Distribution of 24 antibody-positive humans and of rodent species captured.
The mean annual temperature is $29^{\circ} \mathrm{C}$ and ranges from $38.5^{\circ} \mathrm{C}$ in January (summer) to $27^{\circ} \mathrm{C}$ in October (rainy season). There are two rainy seasons: April-June and September-December.

Population survey - In 2009, a cross-sectional study was performed on a sample of the general population of the area $(1,200.000$ people and 180,000 of rural residents). The size of the sample was calculated using the StatCalc module of Epi Info 3.5.1 using a prevalence of $3 \%$ based on the average of studies conducted in South America (Weissenbacher et al. 1996), an error of $1 \%$ and a $95 \%$ confidence interval (CI). The results showed that 279 individuals were required; for convenience, serum was collected from 286 people. The researchers explained the objectives of the study and obtained informed consent from each person. Each participant had a blood sample drawn and completed a questionnaire that included personal data, ethnicity, household and workplace characteristics, occupation, domestic sightings of rodents, recreational activities, duration of residence in the area, history of travel inside and outside the country, previous disease compatible with HPS and contact with a suspected HPS patient. We also included the sera of rural workers and peasants collected in 2002, 2004 and 2005, which were stored at $-70^{\circ} \mathrm{C}$ at the Institute for Tropical Biological Research (IIBT), University of Córdoba (UCO). At that time, the subjects were diagnosed with unknown fever and were seronegative for tropical infections caused by leptospira, rickettsia, dengue and malaria.

Trapping and processing of small mammals - Trapping was performed from November 2008-January 2009. Small mammals were collected each morning and transferred to a field laboratory for processing. After being anesthetised with ketamine, the animals were bled from the retroorbital sinus using heparinised capillary tubes and then killed by cervical dislocation while still anesthetised. Samples of serum, blood, brain, heart, kidney, liver and lung were placed in cryovials and stored in liquid nitrogen until their subsequent analysis at the IIBT. Rodents were tentatively identified in the field, their skulls were removed and their body carcasses were preserved in $10 \%$ formalin. In addition to morphological characteristics, gross karyotypic field preparations and the sequence of the entire cytochrome $b$ gene in the mitochondrial genome were obtained for several representative specimens of each species. Alcohol-preserved voucher specimens were archived at the Museum of Texas Tech University, Lubbock, Texas. Small mammal trapping and processing were performed according to established safety guidelines (Mills et al. 1995).

Serological testing for MACV - Hantavirus antibodies were detected with an IgG ELISA using MACV as an antigen (Levis et al. 1998).

Serological testing for ARAV - Hantavirus antibodies were detected with an IgG ELISA using a recombinant ARAV N protein as the antigen. This recombinant protein was produced by the Virology Research Centre, School of Medicine, University of São Paulo, Ribeirão Preto, Brazil (Figueiredo et al. 2009). 
Comparison to SNV ELISA - We compared the results obtained from the MACV and ARAV ELISAs with results obtained for a subsample of human sera tested during an earlier study. That study and the SNV ELISA have been described (Mattar \& Parra 2004).

Ethics - The wild rodent trapping was authorised by the Ministry of Health of the Republic of Colombia under resolution 008430 of 1993, which establishes the technical and administrative standards for health research involving animals (article 87, paragraphs c, g, h). The study was also approved by the Ethical Committee for Animal Research of the UCO, School of Veterinary Medicine. Human participants were provided a thorough explanation of the study. Surveillance strictly followed the ethical standards of the Helsinki Declaration.

Data analysis - Data were collected using a standardised form and were tabulated using Microsoft Ex$\mathrm{cel}^{\circledR}$. We also used Excel data analysis tools to calculate descriptive statistics.

\section{RESULTS}

Human samples - We analysed 286 human sera using ARAV and MACV antigens. We detected anti-MACV IgG antibodies in $10(3.5 \%)$ samples, whereas using the ARAV antigen, 21 sera were positive (7.34\%). Based on the 95\% $\mathrm{CI}$, there was no statistically significant difference between the proportion positive for MACV antigens and that for ARAV antigens $(\mathrm{p}=0.0648)$ (EpiDat, 3.1, 2006).

Of the 10 samples that were positive for MACV, seven $(70 \%)$ were cross-reactive with ARAV; seven of the 21 ARAV-positive samples were cross-reactive with MACV (Table). Of the 24 positive samples, only two were collected in the prospective phase and the remaining 22 belonged to the IIBT human serum bank and collected as part of a study on febrile syndromes of undiagnosed aetiology (Table).

The 24 IgG-positive human specimens were titrated and an IgM ELISA was performed using the ARAV antigen. Two sera collected in 2009 were IgM positive $(2 / 24$ $=8.33 \%$ ).

TABLE

IgG antibody titre, optical density (OD) and antibody status (positive vs. negative) for samples tested by enzyme immunoassay using antigens of Maciel and Araraquara hantaviruses in the department of Córdoba, Colombia

\begin{tabular}{|c|c|c|c|c|c|}
\hline \multirow[b]{2}{*}{ Serum (year) } & \multirow{2}{*}{$\begin{array}{l}\text { MACV } \\
\text { titre (OD) }\end{array}$} & \multirow{2}{*}{$\begin{array}{l}\text { ARAV } \\
\text { titre (OD) }\end{array}$} & \multicolumn{2}{|c|}{ Positive serum } & \multirow{2}{*}{$\begin{array}{c}\text { Positive to SNV } \\
\text { in } 2004\end{array}$} \\
\hline & & & MACV & ARAV & \\
\hline $11(2002)$ & $1: 6400(0.9680)$ Pos & Neg & Pos & Neg & Pos \\
\hline $41(2002)$ & $1: 6400(0.4490)$ Pos & Neg & Pos & Neg & Pos \\
\hline $48(2002)$ & 1:100 (1.0370) Pos & 1:1600 (0.2550) Pos & Pos & Pos & Pos \\
\hline $55(2002)$ & 1:6400 (1.0740) Pos & Neg & Pos & Neg & Pos \\
\hline $69(2002)$ & 1:100 (1.8830) Pos & 1:25600 (1.168) Pos & Pos & Pos & Pos \\
\hline $92(2002)$ & $1: 100(0.7590)$ Pos & $1: 400(0.4720)$ Pos & Pos & Pos & Pos \\
\hline $171(2002)$ & 1:100 (1.6720) Pos & $1: 25600(0.2350)$ Pos & Pos & Pos & Pos \\
\hline 89 (2002) & 1:100 (1.5430) Pos & 1:25600 (0.1060) Pos & Pos & Pos & Pos \\
\hline 239 (2002) & 1:6400 (1.3910) Pos & $1: 400(0.9070)$ Pos & Pos & Pos & Pos \\
\hline $226(2002)$ & $1: 6400$ (1.5810) Pos & 1:6400 (0.2640) Pos & Pos & Pos & Pos \\
\hline 195 (2002) & Neg & 1:25600 (1.3456) Pos & Neg & Pos & Pos \\
\hline $46(2004)$ & Neg & 1:400 (0.52) Pos & Neg & Pos & $\mathrm{Nd}$ \\
\hline $48(2004)$ & Neg & 1:1600 (1.120) Pos & Neg & Pos & $\mathrm{Nd}$ \\
\hline $92(2004)$ & Neg & 1:400 (1.118) Pos & Neg & Pos & $\mathrm{Nd}$ \\
\hline 69 (2004) & Neg & 1:6400 (1.203) Pos & Neg & Pos & $\mathrm{Nd}$ \\
\hline $31(2005)$ & $\mathrm{Neg}$ & $1: 400(0.3730)$ Pos & Neg & Pos & $\mathrm{Nd}$ \\
\hline $54(2005)$ & Neg & $1: 400(0.9630)$ Pos & Neg & Pos & $\mathrm{Nd}$ \\
\hline $59(2005)$ & Neg & $1: 400(0.3280)$ Pos & Neg & Pos & $\mathrm{Nd}$ \\
\hline $125(2005)$ & Neg & 1:400 (1.1190) Pos & Neg & Pos & $\mathrm{Nd}$ \\
\hline $27(2005)$ & $\mathrm{Neg}$ & $1: 400(0.7840)$ Pos & Neg & Pos & $\mathrm{Nd}$ \\
\hline 45 (2005) & Neg & $1: 400(0.5780)$ Pos & Neg & Pos & $\mathrm{Nd}$ \\
\hline $115(2005)$ & Neg & $1: 400(0.4270)$ Pos & Neg & Pos & $\mathrm{Nd}$ \\
\hline 28 (2009) & Neg & $1: 6400(0.4540)$ Pos & Neg & Pos & $\mathrm{Nd}$ \\
\hline 43 (2009) & Neg & $1: 400(0.4910)$ Pos & Neg & Pos & $\mathrm{Nd}$ \\
\hline
\end{tabular}

Maciel (MACV) and Araraquara (ARAV) results are also compare with those of an ELISA using Sin Nombre virus (SNV) antigen. Nd: not done; Neg: negative; Pos: positive. 
All sera that were positive using either the MACV or ARAV antigen and were also tested using the SNV antigen were SNV positive. Thus, using the SNV ELISA as a standard, the MACV ELISA had a sensitivity of $91 \%$ $(10 / 11)$ and the ARAV ELISA had a sensitivity of $73 \%$ (9/11). Seven sera were positive in all tests (Table).

All 286 participants in the survey were low-income farm workers and 23 males and one female were positive. The age range of individuals with a high seroprevalence was 31-70 years.

Rodents - We captured 322 rodents of seven species in the three municipalities of Córdoba. Two hundred and ten rodents belonged to the family Cricetidae, subfamily Sigmodontinae, including 181 Zygodontomys brevicauda, 28 Oligoryzomys fulvescens and one Oecomys trinitatis. Six rodents were Heteromys anomalus (family Heteromyidae) and one was a Proechimys sp. (family Echimyidae). The remaining 105 rodents belonged to the family Muridae, subfamily Murinae and included 34 Rattus rattus and 71 Mus musculus. The overall trap success rate was $10.2 \%$. Z. brevicauda was the most commonly captured species (Figure). All specimens were antibody negative for MACV and ARAV.

\section{DISCUSSION}

Recognising hantavirus infection in humans and rodents is important not only to identify potential human pathogens, but also to understand how and from where the viruses are transmitted to humans. We detected hantavirus infection approximately twice as frequently using the ARAV antigen as we did when using the MACV antigen. The two people with detectable IgM antibody levels were most likely in the acute phase of infection, but had no symptoms or apparent disease. Both were low-income male farm workers and it is unclear how they had become infected. With many hantaviruses, clear evidence of disease is present when IgM antibodies are detected. In a Brazilian study (Figueiredo et al. 2009), 54\% of HPS patients with active disease were reverse transcriptionpolymerase chain reaction (RT-PCR) positive and all had detectable IgM antibodies against ARAV. As we have demonstrated, the ARAV antigen-based ELISA appears to be a sensitive test for detecting human exposure to hantaviruses in northwestern Colombia.

Mattar and Parra (2004) reported a 13.5\% infection prevalence rate in humans using an ELISA based on a recombinant nucleocapsid protein antigen of SNV. Our prevalence rate obtained using MACV and ARAV antigens was $8.39 \%$, which is similar to that reported by Mattar and Parra (2004). Our results indicate that tests conducted with South American hantavirus antigens could have predictive value and could represent a useful alternative for the diagnosis of hantavirus infection in Colombia. The high viral titres (up to 1:25.600) and odds ratios (ODs) $(>1)$ and the high index of agreement with the MACV antigen ELISA (70\%) suggest that the ARAV antigen ELISA has good detection ability for potential native viral genotypes. Regarding false positives, it is unlikely that the hantavirus antigens used (MACV and ARAV) are cross-reactive with other tropical haemorrhagic viruses (dengue, arenavirus) and bacteria (rick- ettsia, leptospira) and both aetiologies are endemic to the Caribbean area studied. This diagnostic problem is more related to sensitivity than specificity. It is possible to find patients in the Caribbean area of Colombia with coinfections; however, there was no cross-reactivity between the agents mentioned above.

The prevalence of antibodies against hantaviruses in the population of Córdoba ranged between 3.5-13.5\%, depending on the antigen used. The use of a strip immunoblot assay for IgG antibodies based on the recombinant $\mathrm{N}$ protein of the $3 \mathrm{H} 226$ genotype of SNV revealed an antibody prevalence in human populations from the Azuero Peninsula, Panama, of approximately $20 \%$ (Bostik et al. 2000, Vincent et al. 2000, Armien et al. 2004, Bayard et al. 2004). The hantavirus antibody prevalence that we found in Colombian populations is much lower than that reported in neighbouring Panama, Paraguay (40\%) (Ferrer et al. 1998) and Argentina (17\%) (Ferrer et al. 1998), but is higher than that reported for selected populations in neighbouring Venezuela (1.7\%) (Rivas et al. 2003) and the USA (<1\%) (Fulhorst et al. 1997).

We found a significant difference in the ability of the MACV and ARAV antigens to capture hantavirus antibodies in ELISAs in northeastern Colombia. Because MACV and ARAV share $85 \%$ sequence similarity in the $\mathrm{S}$ segment and share the same rodent reservoir (although in different portions of its geographic range), this difference was unexpected.

The findings of high $\mathrm{IgG}$ antibody titres and two IgM-positive humans suggest recent and active hantavirus infections in the study area. However, none of the antibody-positive individuals reported any symptoms suggestive of HPS (Jonsson et al. 2010), indicating that the infections were mild or asymptomatic, as previously reported in Colombia and Brazil (Limongi et al. 2007, Londoño et al. 2011).

Córdoba is only approximately $400 \mathrm{~km}$ from the border of Panama and shares rodent fauna with Panama. These rodents include $O$. fulvescens, the host of Choclo virus, which causes HPS in Panama. Because we captured and tested only 28 O. fulvescens, it is possible that Choclo virus circulates in $O$. fulvescens populations in Colombia, but that our sample size for this host was not sufficiently large to detect it. Z. brevicauda is the host of Calabazo virus in Panama. Calabazo has not been associated with human disease. The genetic characterisation of a hantavirus circulating in Antioquia (the department to the south and east of Córdoba) and RT-PCR analysis of $Z$. brevicauda indicate that this virus is similar to Calabazo virus ( $85 \%$ sequence and $100 \%$ amino acid similarity) (Londoño et al. 2011). The absence of disease in hantavirus-infected humans in Córdoba and our high capture success for Z. brevicauda suggest the possibility that Calabazo virus circulates in its recognised rodent host and may spill over into humans in Córdoba. Our failure to detect Calabazo virus infection in a relatively large sample size $(\mathrm{n}=181)$ of $Z$. brevicauda is puzzling. We did not test the rodent sera using SNV antigen. Therefore, we cannot compare rodent serology results obtained using the ARAV and MACV antigens to the results that would have been obtained using the SNV 
antigen. However, the apparently slightly reduced sensitivity of the ARAV and MACV ELISAs relative to the SNV ELISA for human serological analysis may suggest a similarly decreased sensitivity for rodent serological analysis. We encourage the continued testing of rodent sera using a variety of antigens and the genetic characterisation of any viruses identified.

A higher number of positive humans was found in the towns of Cienaga de Oro and Chima (Córdoba). The failure to identify positive rodents or humans in Planeta Rica is interesting because the highest proportion of $Z$. brevicauda and O. fulvescens (64.91\%) was captured in this area.

Finally, a new diagnostic challenge is posed by our findings. Physicians from the Caribbean area of Colombia should be aware that patients with a febrile syndrome could have not only dengue, malaria, leptospirosis or rickettsial diseases, but also hantavirus infection. Furthermore, because these hantaviruses differ widely in pathogenicity, the genetic characterisation of the infecting hantaviruses is important.

\section{ACKNOWLEDGEMENTS}

To Dr Nelson Alvis, University of Cartagena (Colombia), for statistical review.

\section{REFERENCES}

Alemán A, Iguarán H, Puerta H, Cantillo C, Mills J, Ariz W, Mattar S 2006. Primera evidencia serológica de infección por Hantavirus en roedores, en Colombia. Rev Salud Publica 8 (Suppl. I): 1-12.

Armien B, Pascale M, Bayard V, Munoz C, Mosca I, Guerrero G, Armien A, Quiroz E, Castillo Z, Zaldivar Y 2004. High seroprevalence of hantavirus infection on the Azuero Peninsula of Panama. Am J Trop Med Hyg 70: 682-687.

Bayard V, Kitsutani T, Barria O, Ruedas A, Tinnin S, Muñoz C, De Mosca B, Guerrero G, Kant R, Garcia A 2004. Outbreak of hantavirus pulmonary syndrome, Los Santos, Panama, 1999-2000. Emerg Infect Dis 10: 1635-1642.

Bostik P, Winter J, Ksiazek G, Rollin E, Villinger F, Zaki R, Peters C, Ansari A 2000. Sin nombre virus (SNV) Ig isotype antibody response during acute and convalescent phases of hantavirus pulmonary syndrome. Emerg Infect Dis 6: 184-188.

Calderón G, Pini N, Bolpe J, Levis S, Mills J, Segura E, Guthmann N, Cantoni G, Becker J, Fonollat A 1999. Hantavirus reservoir hosts associated with peridomestic habitats in argentina. Emerg Infect Dis 5: 792-797.

D’Elía G, Pardiñas J, Jayat P, Salazar-Bravo J 2008. Systematics of Necromys (Rodentia, Cricetidae, Sigmodontinae): species limits and groups, with comments on historical biogeography. J Mammal 89: 778-790.

Ferrer JF, Jonsson CB, Esteban E, Galligan D, Basombrio MA, Peralta Ramos M 1998. High prevalence of hantavirus infection in Indian communities of the Paraguayan and Argentinean Gran Chaco. Am J Trop Med Hyg 59: 438-444.

Figueiredo M, Moreli L, Borges A, de Figueiredo G, Badra J, Bisordi I, Suzuki A, Capria S, Padula P 2009. Evaluation of an enzymelinked immunosorbent assay based on Araraquara virus recombinant nucleocapsid protein. Am J Trop Med Hyg 81: 273-276.
Fulhorst CH, Monroe MC, Salas RA, Duno G, Ultrera A, Ksiazek TG, Nichol ST, de Manzione NM, Tovar D, Tesh RB 1997. Isolation, characterization and geographic distribution of Caño Delgadito virus, a newly discovered South American hantavirus (family Bunyaviridae). Virus Res 51: 159-171.

Jonsson B, Figueiredo M, Vapalahti O 2010. A global perspective on hantavirus ecology, epidemiology and disease. Clin Microbiol Rev 23: 412-441.

Levis S, Morzunov SP, Rowe JE, Enria D, Pini N, Calderon G, Sabattini M, St Jeor SC 1998. Genetic diversity and epidemiology of hantaviruses in Argentina. J Infect Dis 177: 529-538.

Limongi JE, da Costa FC, de Paula MB, Pinto RM, Oliveira ML, Pajuaba Neto AA, Borges AS, Ferreira MS 2007. Hantavirus cardiopulmonary syndrome in the Triângulo Mineiro and Alto Paranaíba regions, state of Minas Gerais, 1998-2005: clinical-epidemiological aspects of 23 cases. Rev Soc Bras Med Trop 40: 295-299.

Londoño F, Díaz J, Agudelo-Flórez P, Levis S, Rodas JD 2011. Genetic evidence of hantavirus infections in wild rodents from northwestern Colombia. Vector-Borne Zoonotic Dis 11: 701-708.

Mattar S, Parra M 2004. Serologic evidence of hantavirus infection in humans, Colombia. Emerg Infect Dis 10: 2263-2264.

Mills JN, Childs JE, Ksiazek TG, Peters CJ 1995. Methods for trapping and sampling small mammals for virologic testing, US Department of Health \& Human Services, Public Health Service/ Centers for Disease Control and Prevention, Atlanta, 61 pp.

Moreli ML, de Sousa RLM, Figueiredo LTM 2004. Detection of Brazilian hantavirus by reverse transcription polymerase chain reaction amplification of $\mathrm{N}$ gene in patients with hantavirus cardiopulmonary syndrome. Mem Inst Oswaldo Cruz 99: 633-638.

Padula P, Colavecchia S, Martinez V, Gonzalez Della Valle M, Edelstein A, Miguel S, Russi J, Riquelme M, Colucci N, Almiron M 2000a. Genetic diversity distribution and serological features of hantavirus infection in five countries in South America. J Clin Microbiol 38: 3029-3035.

Puerta H, Cantillo C, Mills J, Hjelle B, Salazar-Bravo J, Mattar S 2006. Hantavirus del nuevo mundo. Ecología y epidemiología de un virus emergente en latinoamérica. Medicina (B Aires) 66: 343-356.

Raboni M, Probst M, Bordignon J, Zeferino A, dos Santos CND 2005. Hantaviruses in Central South America: phylogenetic analysis of the S segment from HPS cases in Paraná, Brazil. J Med Virol 76: $553-562$.

Rivas Y, Moros Z, Moron D, Uzcategui M, Duran Z, Pujol F, Liprandi F, Ludert J 2003. The seroprevalences of anti-hantavirus IgG antibodies among selected Venezuelan populations. Ann Trop Med Parasit 97: 61-67.

Suzuki A, Bisordi I, Levis S, Garcia J, Pereira E, Souza RP, Sugahara T, Pini N, Enria D, Souza L 2004. Identifying rodent hantavirus reservoirs. Emerg Infect Dis 10: 2127-2134.

Vincent J, Quiroz E, Gracia F, Sanchez J, Ksiazek G, Kitsutani T, Ruedas A, Tinnin S, Caceres L, Garcia A 2000. Hantavirus pulmonary syndrome in Panama: identification of novel hantaviruses and their likely reservoirs. Virology 277: 14-19.

Weissenbacher MC, Cura E, Segura EL, Hortal M, Baek LJ, Chu YK, Lee HW 1996. Serological evidence of human hantavirus infection in Argentina, Bolivia and Uruguay. Medicina (B Aires) 56: 17-22. 